\title{
Kaidah-Kaidah Bahasa Arab Non-Fungsional: Upaya Menghadirkan Materi Kaidah Bahasa Arab yang Lebih Mudah
}

\author{
Nurhaqiqi \\ MAN 2 Rembang \\ mbareb72@gmail.com \\ DOI: http://dx.doi.org/10.18326/lisania.v3i1.45-67
}

\begin{abstract}
This study aims to further analyze some Arabic language rules that do not have semantic functions in a sentence; both rules derive from the nahwu and sharaf. The primary source of the study is the Arabic language rules analyzed using the text content (madhmûn) approach. The steps are firstly making an inventory of the rules stated anomaly, then finding its 'illah (reason/cause), and then the conclusions are taken. The results of the study prove that there are Arabic rules that do not have semantic functions. This happens because the motive for its creation is not intended to present new intentions and meanings in a sentence. Among these motives are reasons for sentence efficiency, philosophical nuances and reasons for being mild in pronunciation. The patterns used are al-hadzf, al-ibdl, al-rutbah/taqdîm ta'khîr and al-ziyâdah. The results of this study are not in line with the 'traditional scholars such as al-Mâzinî, (d. 248 H), al-Mubarrid (d. 285 H.), alFarrâ' (d. $189 \mathrm{H}$ ) who said that Arabic linguistics has been perfect and final and there is no need to review on it. On the contrary, this research strengthens the opinion of modern linguists such as Ibn Madlâ (d. 592 H), Syauqî Dhayf (born 1910 AD), Tammam Hasan (born 1918 AD) who said that Arabic science is convoluted, very philosophical and not apparently consistent, which must be reviewed to make it look lighter and easier to learn especially for beginners and finally the impression that Arabic is complicated, difficult and convoluted can be avoided.
\end{abstract}

Keywords: Arabic Language, Anomaly, Semantic Function

\begin{abstract}
Abstrak
Penelitian ini bertujuan untuk menganalisa lebih jauh beberapa kaidah dalam bahasa Arab yang tidak memiliki fungsi semantik dalam sebuah kalimat, baik kaidah-kaidah yang berasal dari ilmu nahwu maupun sharaf. Sumber primer penelitian adalah kaidah-kaidah bahasa Arab dianalisis dengan menggunakan pendekatan isi (content/madhmûn) teks. Adapun langkahlangkahnya yaitu melakukan inventarisasi terhadap kaidah yang dinyatakan anomali, kemudian dicari 'illah (alasan) mengapa sampai terjadi anomali, dan kemudian diambil kesimpulan. Hasil penelitian membuktikan bahwa terdapat kaidah-kaidah bahasa Arab yang tidak memiliki fungsi semantik. Hal ini terjadi karena motif penciptaannya tidak dimaksudkan untuk menghadirkan maksud dan makna baru dalam sebuah kalimat. Motif itu di
\end{abstract}


antaranya adalah alasan efisiensi kalimat, bernuansa filosofis dan alasan agar ringan dalam pengucapannya. Adapun pola-pola yang digunakan adalah alhadzf, al-ibdâl, al-rutbah/taqdîm ta'khîr dan al-ziyâdah. Hasil penelitian ini tidak sejalan dengan para ulama' tradisional seperti al-Mâzinî (w. 248 H), alMubarrid (w. 285 H), al-Farrâ' (w. 189 H) yang mengatakan bahwa ilmu bahasa Arab itu telah sempurna dan final dan tidak perlu lagi dilakukan pengkajian-pengkajian ulang terhadapnya. Sebaliknya penelitian ini memperkuat pendapat ahli bahasa modern seperti Ibn Madlâ (wafat $592 \mathrm{H}$ ), Syauqî Dhayf (lahir 1910 M), Tammam Hasan, (lahir 1918 M) yang mengatakan bahwa ilmu bahasa Arab itu berbelit-belit, sangat filosofis dan terkesan tidak konsisten, yang harus dikaji ulang agar terlihat lebih ringan dan mudah dipelajari khususnya bagi pembelajar pemula dan ujungya kesan bahwa bahasa Arab itu rumit, sulit dan berbelit-belit bisa dihindari.

Kata Kunci: Kaidah Bahasa Arab, Anomali, Non-Fungsional

\section{Pendahuluan}

Kedudukan kaidah (gramatika) dalam sebuah bahasa memiliki fungsi yang sangat penting. Kaidah dibuat untuk memfasilitasi proses berbahasa atau berkomunikasi. Melalui kaidah, pembicara atau penulis dapat mengeksprsikan makna, ide dan pikiran kepada pihak lain melalui pengorganisasian struktur kalimat yang fungsional serta menanggulangi ambiguitas sebuah kalimat. Hal ini sebagaimana yang dikatakan oleh Hamid al-Mukmin -ketika mengomentari perjalanan ilmu nahwu bahwa kaidah bahasa dapat menjaga lisan dalam berkomunikasi dari kesalahan berbahasa (laĥn). (Ĥ̂mid al-Mu'min, 1985: 23-24).

Namun demikian bukan berarti semua kaidah bahasa memiliki fungsi signifikan dalam membangun sebuah makna dan maksud kalimat. Hal ini bisa dipahami dari apa yang dikatakan oleh kritikus bahasa A. Aĥmad al-Ĥamlawi (lahir 1856 M.) ketika ia mengomentari terhadap kaidah 'i'lâl dan ibdâl yang mengatakan bahwa kaidah-kaidah i'lâl dan ibdâl muncul dilatarbelakangi oleh kondisi sosial masyarakat Arab pada zaman dahulu yang tidak banyak kesibukan, sehingga daripada nganggur, sambil menggembala kambing dan onta, mereka menciptakan kaidah 'i'lâl dan ibdâl untuk mereka-reka persoalan bahasa (al-Ĥamlâwî, 1957: 22). 
Dalam bidang $n a \hat{h} w$, kaidah-kaidah yang disinyalir sebagai tindakan yang mengada-ada adalah sebagaimana yang disampaikan oleh Ibn Madlâ (w. 592) sebagai berikut : para nuĥhh membuat teori atau analisa tentang "membuang sebuah 'âmil', yang sebenarnya belum tentu terjadi demikian, karena hampir pasti yang demikian itu tidak pernah terpikirkan oleh mutakallim sebelum atau ketika dia bicara, contoh: أزيدا ضربته؟ , oleh para nuhat nashabnya kata زيدا disebabkan oleh adanya 'âmil yang terbuang, persoalannya adalah benarkah demikian adanya ?, atau ini hanya merupakan reka-reka oleh para nuĥât!. Teori atau analisa semacam ini menurut Ibnu Madlâ merupakan konsekuensi dari adanya kaidah yang dibuat oleh mereka sendiri tentang 'âmil, yaitu bahwa sesuatu yang manshûb itu pasti karena ada nâshib. Teori yang lain adalah tentang "pembuangan ( $a l-\hat{h} a d z f)$ " dan ini lebih tidak logis lagi, yaitu membuang 'âmil yang justru menyebabkan pada perubahan pola kalimat, contoh: يا قمر الدين (huruf ra dibaca fathah) oleh para nuĥt nashabnya kata قمر disebabkan oleh terbuangnya kata أدعو yang jatuh sebelumnya, sehingga kalau dikembalikan, kalimat itu akan menjadi أدعو قمر الدين. Menurut Ibnu Madlâ, jika kalimat يا قمر الدين Sebagai ganti dari kata أدعو قمر الدين, maka pola kalimat tersebut akan berubah dari kalam insyâ' menjadi kalam khabar (Madlâ, tt: 26-27). Contoh lain misalnya fenomena yang terjadi pada kaidah jumlah ismiyyah. Kaidah aslinya berbunyi bahwa jumlah ismiyyah itu terdiri dari mubtada' dan khabar, kemudian muncul kaidah cabang yang mengharuskan membuang mubtada' (Musthafa, 1993: 258), contoh: فف ذمتي لأفعلنّ كذ, kalimat ini kalau di i'rab sebagai berikut: kata في ذفتي adalah khabar, sedangkan mubtada-'nya maĥhdzûf (dibuang), yaitu kata عهـ, maka kalau ditulis secara lengkap adalah كذا في ذمتي عهد لأفعلّ.

Muhbib dalam disertasinya yang berjudul Metode Penelitian dan Pembelajaran Nahw: Studi Teori Linguistik Tammâm Ĥassân, mengatakan bahwa terdapat persoalan-persoalan yang berkenaan dengan $n a \hat{h} w$ seperti itsbât (afirmasi), nafy (pengingkaran), tawkîd (penguatan, pemastian), rutbah 
(urutan kata dalam kalimat) seperti: taqdîm (peletakan urutan/posisi kata didahulukan dari yang semestinya), ta'khîr (peletakan urutan/posisi kata di bagian akhir dari yang semestinya), jumlah taqrîriyyah (kalimat berita), jumlah istifhâmiyyah (kalimat tanya), dan jumlah syarthiyyah (kalimat kondisional). Selain itu, kajian nahw menjadi terfokus pada aspek lahiriyah (mabnâ, lafzhi, bentuk) semata, tidak menyentuh aspek-aspek lain yang substansial yang berkaitan dengan kategori dan relasi antarkata dalam sebuah struktur kalimat (Muhbib, 2008: 93).

Fenomena kaidah bahasa seperti di atas, biasanya terjadi pada kaidah far'iyyah (kaidah cabang), yang selanjutnya fenomena itu disebut sebagai sebuah anomali bahasa (penyimpangan bahasa) yang sering kali tidak memiliki fungsi signifikan didalam menghadirkan makna dalam sebuah kalimat. Maka berdasarkan ini, penulis tergerak menganalisa lebih jauh beberapa kaidah lain dalam bahasa Arab yang diyakini tidak memiliki fungsi semantic dalam sebuah kalimat, baik kaidah-kaidah yang berasal dari ilmu nahw maupun sharaf.

\section{Metode Penelitian}

Berdasarkan tujuan dari penelitian ini yaitu untuk mengetahui sejauh mana persoalan kaidah bahasa itu terjadi, dan benarkah terdapat kaidahkaidah yang secara signifikan kurang memberi warna makna dalam sebuah kalimat, maka penelitian yang akan dilakukan adalah penelitian kualitatif. Dalam hal ini penulis akan menggunakan metode kajian pustaka dengan memadukannya dengan metode pendekatan isi (content/madhmûn) teks (Sulaiman, 2002: 287). Pendekatan ini akan dipergunakan oleh penulis untuk mengkaji fenomena kaidah-kaidah far'iyyah (cabang) terhadap kaidah-kaidah dasar/al-Qawâ'idu al-Ashliyah, khususnya yang tidak memiliki fungsi semantic (menghadirkan makna baru) dalam sebuah kalimat.

Data pokok yang akan disajikan dan akan dianalisis oleh penulis dalam penelitian ini adalah kaidah-kaidah bahasa Arab far'iyyah (cabang) yang khususnya mengalami penyimpangan dari kaidah pokok/dasar. Data itu secara garis besar meliputi kaidah-kaidah yang termasuk dalam lingkup ilmu 
$n a \hat{h} w$ dan Kaidah-kaidah yang termasuk dalam lingkup ilmu sharf. Untuk selanjutnya data-data tersebut akan penulis analisa agar diketahui penyebab terjadinya anomali, serta implikasinya terhadap perubahan makna dan maksud didalam sebuah kalimat. Kemudian data-data itu ditetapkan sebagai data primer. Sedangkan sumber data tersebut diambil dari kitab Jâmi'u alDurûs karya Mushthafâ Ghalâyainî dan kitab-kitab naĥh lainnya.

Sedangkan sumber skunder yang penulis butuhkan adalah kitab-kitab ushûlu al-naĥwi, yaitu kitab-kitab yang membicarakan tentang prinsipprinsip yang melandasi ilmu naĥw dalam berbagai persoalan dan aplikasinya. Selain itu penulis juga menjadikan buku-buku sejarah pengkodifikasian ilmu naĥw juga menjadi sumber skunder yang lain.

Setelah penulis menetapkan data, langkah selanjutnya adalah mengumpulkannya serta menganalisisnya. Langkah-langkah itu adalah: 1) Mengidentifikasi kaidah-kaidah yang menyimpang dari kaidah pokoknya. Langkah ini dilakukan dengan cara membandingkan antara kaidah pokok dan kaidah cabangnya. Jika kaidah cabang tidak selaras dengan kaidah pokok, maka kaidah cabang tersebut ditetapkan sebagai data. 2) Mengelompokkan data-data itu sesuai kategori. 3) Mengidentifikasi penjelasan tentang sebab dan maksud diciptakannya kaidah far'iyyah tersebut dari para nûhâh. 4) Menganalisis makna-makna yang dimungkinkan muncul dari kalimat yang menggunakan kaidah far'iyyah tersebut. 5) Merumuskan dan menyimpulkan tentang peranan penggunaan kaidah far'iyyah tersebut dalam kalimat, dari segi kekuatannya didalam mewarnai dan merubah makna dan maksud dari kalimat itu.

\section{Kaidah (Gramatika) dalam Bahasa Arab}

Bahasa merupakan bagian dari budaya manusia. Untuk keperluan interaksi, mereka membutuhkan sebuah media yang mampu dijangkau oleh setiap anggota kelompok dan telah disepakati sebagai alat komunikasi. Kesepakatan itu tidak berlangsung melalui sebuah forum formal melainkan mengalir begitu saja berdasarkan kebiasaan. Tidak ada batasan-batasan bagi siapa saja untuk melahirkan sebuah kata baru, maka kekayaan kata dalam 
sebuah bahasa tidak akan terbendung oleh siapapun. Aktifitas manusia yang makin hari makin komplek, menyebabkan bahasa terus berkembang dan makin komplek, maka untuk menjaga konsistensinya lahirlah kaidah bahasa.

Kekomplekan bahasa menyebabkan kaidah-kaidah yang telah ada, tidak mampu mengakomodir terhadap unsur bahasa yang memiliki karakteristik-karakteristik tertentu karena adanya perkembangan bahasa. Hal ini seperti yang disampaikan oleh Quraish Syihab ketika menanggapi tentang gramatika bahasa Arab, dia berkata: Adanya fenomena anomali, harus diakui sebagai keterbatasan kaidah standar (mi'yari), dan untuk mengakomodir fenomena itu para ulama' gramatika kemudian memperkenalkan neologisme syâz (fenomena linguistik yang jarang terjadi) atau ististna' (pengecualian), dan hal tersebut dimaksudkan untuk menjawab persolan-persoalan linguistik dalam al-Qur'an (Quraish, 2006: 32).

Tidak menutup kemungkinan bahwa kompleksitas sebuah bahasa tersebut akibat kecenderungan yang berlebihan terhadap tata bahasa tradisional, yang oleh banyak kalangan dianggap telah ketinggalan atau tidak relevan lagi karena memiliki banyak kelemahan. Diantara kritik-kritik yang dilontarkan oleh ahli ilmu bahasa modern terkait ilmu bahasa tradisional adalah ketidakberdayaan kaidah bahasa dalam mengakomodir kompleksitas bahasa tergambar jelas dalam perkataan Tammam Hasan sebagai berikut: "Susunan kalimat itu seharusnya begini, boleh juga begitu kecuali dalam halhal tertentu", atau "Susunan kalimat itu seharusnya begini, tapi kadangkadang juga boleh begitu", atau "Susunan kalimat itu seharusnya tidak demikian, tapi karena kalimat itu mengandung faedah, bolehlah", yang selanjutnya kaidah pertama disebut dengan al-Qâ'idah al-Ashliyyah, sedangkan yang kedua disebut dengan al-Qâ'idah al-Far'iyyah (Tammâm, 2000: 108).

Berikut akan disampaikan beberapa kaidah anomali yang tidak memiliki peran signifikan dalam perubahan makna dan atau maksud dalam sebuah kalimat. Kaidah tersebut terkategori menjadi tiga, yaitu anomali pada huruf, anomali pada i'rob dan anomali pada tarkib. Kerena keterbatasan 
ruang, maka pada kesempatan ini hanya disajikan kaidah anomali pada tarkib.

\section{Keharusan membuang mubtada' dan atau khabar}

Seperti yang telah diketahui bersama, bahwa jumlah ismiyyah dianggap sah apabila memenuhi dua unsurnya, yaitu mubtada' dan khabar. Namun dalam beberapa kasus terdapat suatu kaidah lain yang mengharuskan membuang mubtada' dan atau khabar dari jumlah/kalimat. Berdasarkan kaidah inilah kaidah ini bisa dikatakan sebagai sebuah kaidah yang menyimpang/anomali terhadap kaidah dasarnya, yaitu bahwa yang disebut jumlah ismiyyah adalah jumlah yang terdiri dari mubtada' dan khabar.

Berkenaan dengan keharusan membuang mubtada' yang dalam kontek penelitian ini kaidah itu disebut dengan al-qâ'idah al-fariyyah. Kaidah itu menyatakan bahwa dalam kasus-kasus tertentu, mubtada' wajib dibuang dari kalimat, sehingga yang terlihat hanya khabar-nya. Kasus-kasus yang dimaksud adalah : 1) Jika terdapat petunjuk, bahwa mubtada' merupakan jawâb al-qasam, contoh: ف ذمتى لأفعلن كذا asalnya adalah 2) Jika khabar-nya berupa masdar yang menggantikan pekerjaan mubtada', contohnya صبر بميل، سمع وطاعة yang aslinya صبرى صبر جميل، أمرى سمع وطاعة Jika dimaksudkan untuk memberi sifat "pujian" atau "celaan" dengan menggunakan kata نعب dan نعم نعم الرجل (هو) contoh itu pada mulanya نعم الرجل أبو طالب بئس الرجل أبو لهب contoh Jika khabar pada hakikatnya berupa kata sifat, yang mensifati kata sebelumnya, namun kemudian dihilangkan kesifatannya dan diganti dengan mubtada' untuk memberi tekanan

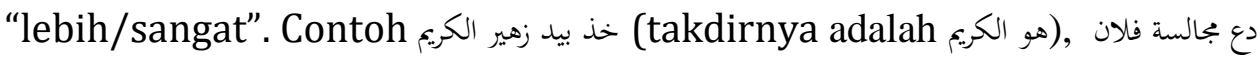

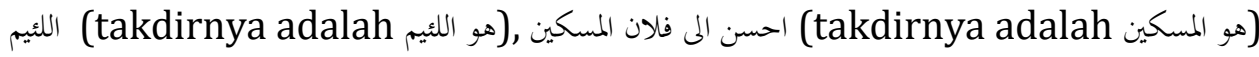
(Mushthofa, tt: 372-373). 
Sedangkan yang berhubungan dengan kaidah "keharusan membuang khabar", kaidah itu mengatur sebagai berikut: dalam kasus-kasus tertentu khabar harus dibuang dari kalimat,sehingga yang nampak hanya mubtada'-nya. Kasus-kasus yang dimaksud adalah : 1) Apabila khabar itu menunjukkan kepada suatu sifat yang mutlak, yakni khabar itu tanpa disebutkan sudah secara otomatis مستقر، melekat pada mubtada'-nya. Khabar itu biasanya berupa kata الجنة Contoh لولا، لوما atau khabar itu terletak setelah kata موجود/ موجودة حاصل العلم في الصدور ,(الجنة موجودة تحت أقدام الأمهات takdirnya adalah) تحت أقدام الأمهات (takdirnya adalah لولا الكتابة لضاع أكثر العلمdan العلم مستقر فن الصدور (takdirnya adalah لولا الكتابة موجودة لضاع أكثر العلم). Ketentuan keharusan membuang khabar ini sebenarnya juga tidak mutlak. Dalam kondisi tertentu, walaupun didahului kata لولا, khabar tidak boleh dibuang, karena tidak terdapat petunjuk (dalil) tentang hal itu. Contoh: Nabi bersabda: قومك kata berposisi sebagai mubtada', dan رابيت قومك حديثوا عهد بجاهلية لأقمت dikhithabkan kepada Aisyah, sementara kata حديثوا عهد berposisi sebagai khabar (Rahman, 2001: 486). 2) Apabila khabar tersebut merupakan pasangan dari mubtada' sharîh dalam sumpah. Contoh لَعَرك لأفعلن (takdirnya adalah لَعَرُك قسمى لأفعلن). 3) Mubtada' berupa mashdar atau isim tafdlîl yang dimudlaf-kan kepada mashdar, dan setelahnya berupa ĥal yang menyebabkan tidak memungkinkannya menyebut khabar kecuali hâl tersebut berubah strukturnya. Contoh أفضل عملك الخير مستتر (takdirnya أفضل عملك الخير حاصل في حال استتارك). 4) Apabila khabar terletak setelah al-waw muta'aiyyîn yang memiliki makna "مل /مع فعل Contoh". (كل امرئ وفعله مقترنان (takdirnya adalah) امرئ وما فعل (Mushthofa, tt: 373-374).

Mencermati kaidah-kaidah di atas, nampaknya masih menyisakan pertanyaan-pertanyaan, mengapa fenomena membuang mubtada' atau khabar tersebut harus dilakukan?, akankah tanpa 
membuang mubtada' atau khabar dalam kasus-kasus tersebut akan menyebabkan rusaknya susunan kalimat?. Berdasarkan uaraian kaidah tersebut di atas terdapat beberapa catatan.

Kasus kalimat yang pertama pada dasarnya memang tidak membutuhkan akan kehadiran kata yang selanjutnya diklaim sebagai mubtada' yaitu kata عهد Kمتى Kata sebagaimana yang terdapat dalam contoh, dari segi makna secara implisit di dalamnya sudah mengandung makna "sebuah tanggung jawab yang harus dilakukan". Oleh karena itu kata عهد/ميثاق disebutkan atau tidak disebutkan, sebenarnya sudah bisa dimengerti apa kandungan kalimat tersebut. Yang demikian juga yang terjadi terhadap kasus kedua, ketiga dan keempat. Namun yang masih menyisakan persoalan adalah kenapa membuang mubtada' adalah sebuah keharusan, padahal seandainya mubtada' tersebut tidak dibuang, selain struktur kalimat akan terlihat lengkap -ada mubtada' sekaligus ada khabar-nya-, justeru akan membantu seseorang di dalam mengkaji strukturnya, dan juga penyebutan itu tidak akan merusak makna, kecuali hanya terlihat siasia penyebutannya.

Dalam hal ini Ibnu Madlâ (w. 592 H) juga mengisyaratkan bahwa fenomena الحذف -khususnya membuang 'âmil- adalah tindakan yang mengada-ada untuk kasus-kasus tertentu, dia berkata bahwa pembuangan terhadap 'âmil yang dilakukan oleh para nuĥât didasarkan atas tiga motif, yaitu: 1) karena mukhâthab telah mengetahuinya, artinya walaupun 'âmil tersebut dibuang, mukhâthab tetap memahami kalimat yang dimaksud, sebagai contoh: وقيل للذين اتقَوا ماذا (أنزل خيرا (اي ) ' أَنَك ربكم قالوا خيرا 'Âmil itu dibuang, padahal 'âmil yang terbuang itu tidak pernah terpikirkan oleh mutakallim, contoh: أزيدا ضربته؟. Oleh para nuĥt nashabnya kata زيدا disebabkan oleh adanya 'âmil yang terbuang dan analisa semacam ini -kata Ibnu Madlâ- akibat adanya kaidah yang dibuat oleh mereka tentang 'âmil, yaitu bahwa 
sesuatu yang manshûb itu pasti karena ada nâshib, 3) pembuangan yang lebih tidak logis lagi, yaitu membuang 'âmil yang justeru menyebabkan pada perubahan pola kalimat, contoh: يا عبد الله oleh para nuĥt nashabnya kata عبد disebabkan oleh terbuangnya kata أدعو yang jatuh sebelumnya, sehingga kalau dikembalikan, kalimat itu akan menjadi أدعو عبد الدهو. Menurut Ibnu Madlâ, jika kalimat أدعو عبد الله sebagai ganti dari kata يا عبد الثه , maka pola kalimat tersebut akan berubah dari kalam insyâ' menjadi kalam khabar (Madho, tt: 26-27).

Namun demikian Ibn Jinnî (321-392 H) tetap mengatakan dalam bukunya al-Khashâish bahwa didalam prinsip الحذ, tindakan "membuang" berarti yang dibuang itu pastilah "tidak dibutuhkan", dan ia memastikan tidak terjadi pada inti kalimat (Jinny, 1952: 263). Jadi pembuangan itu dilakukan selain dari segi makna tidak dibutuhkan, juga kata yang terbuang itu bukan inti kalimat. Dan oleh karena itulah, para ulama' yang menciptakan aturan ini ada beberapa kemungkinan. Pertama, berarti telah melakukan pembiaran atau kalau malah bukan sengaja menciptakan sebuah kaidah baru -dalam kontek penelitian ini disebut dengan al-qấidah al-far'iyyah- yang anomali, karena tidak sesuai dengan kaidah dasarnya. Kedua, bisa jadi unsur-unsur yang diakui sebagai yang dibuang itu, memang sejak awal tidak ada, atau dengan kata lain fenomena membuang itu hanya merupakan ijtihat yang subektif para pencipta ilmu naĥw sesuai dengan cara berpikir dan logika masing-masing. Hal ini terlihat dari sikap mereka yang berbeda ketika menyikapi kasus berikut: بئس الرجل أبو لهب Sebagian mengatakan bahwa kata أبو لهب dianggap sebagai khabar dan mubtada'-nya adalah $ه$ yang dibuang sebagaimana dijelaskan di atas, sebagaian lagi mengatakan bahwa kata أبو له adalah sebagai mubtada' yang diakhirkan, sedangkan khabar-nya adalah kata بئس الرجل أبو لهب بئ الرجل yang didahulukan, jadi kalimat itu aslinya berbunyi 
Dugaan bahwa kaidah-kaidah ini merupakan suatu hasil cipta karya para ulama' nuĥât, barangkali sejalan dengan apa yang dikatakan oleh Tammâm Ĥassân (lahir 1918 M) bahwa kaidah itu adalah shinâ'ah (Tammam, 2006: 438).

\section{Mubtada' yang bukan ism ma'rifat (definite)}

Hukum-hukum mubtada' secara umum ada lima, di antara hukum itu adalah bahwa mubtada' disyaratkan harus berupa isim ma'rifat. Alasan yang dibangun adalah karena mubtada' merupakan inti kalimat, maka mubtada' harus memiliki kejelasan identitas agar

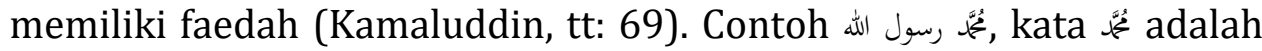
isim ma'rifat, yaitu isim yang bagi pendengarnya tidak perlu menduga-duga siapa itu Muhammad karena kejelasan identitasnya. Hal ini berbeda dengan contoh berikut: رجل رسول الل مata nakirah yaitu isim yang belum jelas identitasnya, maka terhadap contoh tersebut kata رجل bagi yang mendengarnya masih belum jelas karena akan mendatangkan banyak kemungkinan, bisa saja nabi Muhammad, nabi Isa, nabi Musa atau nabi-nabi yang lain.

Persoalannya adalah banyak dijumpai dalam kalimat, sebuah mubtada' yang bukan berupa isim ma'rifat dan ini juga tetap dianggap sebagai mubtada' serta diatur dengan kaidah-kaidah yang telah ditentukan. Toleransi ini diperuntukkan bagi 14 situasi sebagai berikut : 1) Jika kata itu berupa susunan idlafah. Contoh خمس صلوات كتبهن اله Mubtada' dari kalimat tersebut adalah kata خمس صلوات berupa susunan idlâfah. 2) Jika kata itu berupa susunan sifah maushûf. Contoh لعبد مؤمن .خير من مشرك . Mubtada' dari kalimat tersebut adalah susunan sifah maushûf عبد مؤمن 3) Jika khabar-nya berupa dzarf atau jar majrûr dan didahulukan atas mubtada'-nya. Contoh كل أجل كتاب، وفوق كل ذى علم عليم. Mubtada' dari kalimat ini adalah kata كتيم dan عتيب, sedangkan khabarnya adalah فوق كل ذى علم berupa dzaraf dan لكل أجل yang keduanya 
didahulukan atas mubtada', 4) Kata itu terletak setelah huruf nâfí, ما أحد منا، أله مع الله، لولا اصطبار لأودى، istifhâm, lau lâ dan idzan fujâ'iyah. Contoh Mubtada' dari kalimat tersebut adalah ما مأحد didahului

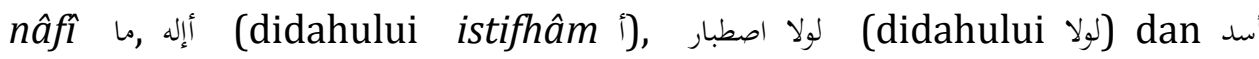
(didahului إٕذا. 5). Jika kata itu berupa 'âmilah ( yang mengamalkan ). Contoh 6) Kata itu termasuk kata yang mubhamah, seperti ism syarth, istifhâm, mâ ta'ajjubiyah dan kam khabariyah. Contoh من يجتهد يفلح ، من مجتهد ، كم علما فن صدرك ، ما أحسنَ العلمَ ,كم مأثرة لك 7) Kata itu mengandung do'a. Contoh سلام عليكم ، ويل للمطففين, Kata itu berlawanan dari maushûf-nya. Contoh عالم خير من جاهل Kata itu berkedudukan sebagai jumlah ĥâliyah dan padanya terdapat huruf alwaw. Contoh سرينا ونم قد أضاء 10) Pembicara menghendaki pemisahan/pembagian terhadap kata itu. Contoh بوم نُساء ,ثوب لبثت وثوب أجُر . .ويوم نُسرّ Kata itu diathaf-kan kepada ism ma'rifat dan atau sebaliknya. Contoh النحو يتعلمان خالد ورجل يتعلمان النحو رجل وخالد Kata itu diathaf-kan kepada ism nakirah maushûfah dan atau sebaliknya. Contoh 13 (13 اعة وقول معروفة أمثل من غيرها ,قول معروف ومغفرة خير من صدقة يتبعها أذى Berdasarkan kontek kalimatnya, hanya kata itulah yang memungkinkan adanya. Contoh رجل أقوى من امرأة, dan 14) Kata itu merupakan "jawaban" dari sebuah pertanyaan. Contoh رجل kata ini merupakan jawaban dari pertanyaan من عندك؟ (Mushthofa, tt: 369-371).

Dalam ilmu bahasa Arab terdapat beberapa bentuk susunan sebuah kalimat atau yang sering disebut al- murakkab, selain murakkab idlâfî, bayânî, 'athfî. mazjî̀, dan 'adadî juga terdapat murakkab isnâdî . Murakkab isnâdî adalah bersandarnya sebuah kata terhadap kata yang lain. Kata yang bersandar disebut dengan almusnad dan kata yang disandari disebut dengan al-musnad ilaih. Oleh 
karena itu murakkab isnâdî itu terdiri dari al-musnad dan al-musnad ilaih. Contoh يفلح المتجهد، الطالب ناجح disebut dengan al-musnad الطالب data ناجح kaih karena kata tersebut yang menjadi sandaran, sedangkan kata disebut dengan al-musnad karena kata tersebut menyandarkan dirinya kepada kata الطالب. Demikian juga terhadap contoh yang kedua, kata البحتهد adalah al-musnad ilaih, sedangkan kata يفلح adalah al-musnad.

Berkaitan dengan pokok permasalahan ini, maka mubtada' pada dasarnya disebut al-musnad ilaih karena keberadaannya menjadi sandaran dari khabar-nya, sedangkan khabar itu sendiri disebut almusnad karena ia bersandar pada mubtada'. Dalam perspektif ini maka untuk mengetahui mana yang mubtada' dan mana yang khabar dalam jumlah ismiyyah, cukup memahami tentang apa yang dimaksud dengan al-musnad dan apa pula yang dimaksud dengan al-musnad ilaih, sehingga pembelajar tidak perlu dipusingkan dengan adanya mubtada' yang diakhirkan dan khabar yang didahulukan, serta tidak dibingungkan dengan persyaratan keharusan bahwa mubtada' harus ism ma'rifat (definite). Jika terdapat sebuah kata dalam jumlah ismiyyah yang menjadi sandaran dari kata yang lain, apakah kata itu telah sesuai dengan ciri-ciri ism ma'rifat (definite) atau bukan -jika bukan berupa ism ma'rifat (definite), oleh para nuĥht kata itu disebut nakirah mufídah-, maka dipastikan kata itu adalah mubtada', sedangkan kata yang bersandar itu dinamakan khabar.

Menurut hemat penulis, penyebutan persyaratan bahwa mubtada' harus ism ma'rifah bisa dikatakan sebagai sesuatu yang siasia, karena pada dasarnya ketika seseorang bermaksud membangun kalimat jumlah ismiyyah (nominal sentence), akan dengan sendirinya bahwa kalimat itu terdiri dari al-musnad dan al-musnad ilaih dan almusnad ilaih-nya secara otomatis akan berupa kata yang jelas identitasnya -yang dalam ilmu nahww disebut dengan ism ma'rifah (definite)-, walaupun bisa jadi ia tidak mengerti apa yang dimaksud dengan ism ma'rifat itu. Bukankah banyak sekali orang sedang 
berbahasa, namun ia sendiri tidak mengerti ilmu bahasa?. Selain itu, jika al-musnad ilaih yang ia sampaikan tidak jelas siapa/apa yang dimaksud, orang yang mendengar dipastikan akan bertanya siapa/apa yang ia maksudkan, karena jumlah ismiyah adalah sebuah kalimat yang dimaksudkan untuk memberikan informasi dan menjelaskan fakta, karena itulah harus jelas siapa/apa yang diinformasikan. Hal ini sebagaimana yang disampaikan oleh Tarigan ketika menyampaikan peran dan fungsi bahasa, dia berkata bahwa diantara peran dan fungsi bahasa adalah fungsi pemberian (the representational function) yaitu penggunaan bahasa untuk membuat pernyataan-pernyataan, menyampaikan fakta-fakta dan pengetahuan, menjelaskan atau melaporkan, dengan kata lain menggambarkan realitas yang sebenarnya, seperti: Matahari panas, garam asin dan lain-lain (Tarigan, 1987: 6).

Terlepas dari perdebatan di atas, sudah menjadi kenyataan bahwa terdapat pengakuan oleh para nuĥat, bahwa walaupun bukan ism ma'rifat (definite), contoh-contoh sebagaimana di atas telah diakui sebagai mubtada', yang selanjutnya isim-isim tersebut dinamakan nakirah mufídah. Oleh karena itulah kaidah ini digolongkan sebagai sebuah anomali al-qấidah al-fariyyah. Dikatakan demikian selain karena kaidah ini merupakan pecahan dari kaidah dasar tentang hukum-hukum mubtada', juga telah menyimpang dari kaidah dasarnya, yaitu keharusan mubtada' dari ism ma'rifat (definite).

\section{Maf'ûl li-Ajlih}

Dalam bahasa Arab, untuk menjelaskan maksud dan tujuan dilaksanakannya sebuah pekerjaan, terdapat sebuah instrumen yang disebut dengan قلام التعليل. Misalnya: قمت لإكرام الأستاذ (saya berdiri untuk menghormati professor). Huruf lam pada kata اكرام itulah yang disebut dengan lâm al-ta'lîl, yang keberadaannya dimaksudkan untuk menjelaskan maksud pekerjaan "berdiri" yang dilakukan oleh fâ'il (subyek) (Hisyam, tt: 316). 
Namun, untuk menjelaskan maksud yang sama sebagaimana di atas, yakni menerangkan maksud dan tujuan dilaksanakannya sebuah pekerjaan, terdapat cara yang lain, yaitu dengan menggunakan prosedur maf'ûl li-Ajlih, yaitu penyebutan masdar (yang maknanya berhubungan dengan pekerjaan hati), yang bertujuan untuk menjelaskan maksud sebuah pekerjaan, dalam waktu yang bersamaan (Mushthofa, tt: 43). Berdasarkan definisi tersebut maka dalam penyusunan struktur kalimat maf'ul li-ajlih terdapat minimal tiga syarat, yaitu maf'ul li-ajlih itu harus berupa mashdar, maf'ul li-ajlih harus memiliki hubungan sebab akibat dengan kata kerja sebelumnya, dan maf'ul li-ajlih tersebut merupakan satu-satunya target pekerjaan yang akan dilakukan oleh subyek serta waktunya bersamaan dengan pekerjaan subyek saat itu. Contoh: اغتربت رغبة في العلم artinya: "saya melakukan ini (pekerjaan yang aneh), semata-mata untuk mendapatkan ilmu".

Kedua cara di atas (menggunakan pola lâm al-ta'lîl dan pola masdar/maf'ûl li ajlih) memiliki maksud dan tujuan yang sama, namun dengan menggunakan cara yang berbeda. Dalam kontek pembelajaran, cara pertama (lam al-ta'lîl) tentu lebih mudah karena menggunakan instrumen yang nyata, yaitu menggunakan lam dan disambung dengan mashdar yang cara kerjanya mengikuti prosedur jar majrûr. Sedangkan cara yang kedua (maf'ul li-ajlih) lebih abstrak, karena dalam kerjanya melibatkan syarat-syarat abstrak yang tidak mudah untuk dicerna oleh pembelajar.

Berdasarkan penjelasan tersebut di atas, dapat diketahui bahwa kedua kaidah itu tidak saling bertentangan, justeru dan disatu sisi ini menunjukkan kelebihan bahasa Arab, karena memiliki banyak cara untuk mengungkapkan maksud yang sama, namun disisi lain bisa membebani pembelajar, karena menjadikan padatnya materi pembelajaran. Selain itu juga bisa difahami bahwa kehadiran kaidah maf'ûl liajlih tidak dimaksudkan untuk mendatangkan makna baru 
atau maksud tertentu, melainkan merupakan ragam struktur kalimat lain di samping penggunaan lam al-ta'lîl untuk menjelaskan maksud dilakukannya sebuah pekerjaan. Oleh karena itulah kehadirannya bukan sesuatu yang dibutuhkan, walaupun tetap memiliki manfaat.

\section{Keharusan membuang âmil yang menashabkan maf'ûl fîh/dlarf}

Maf'ûl fîh/dlarf adalah isim-isim tertentu yang dibaca nashab (accusative) yang di dalamnya mengandung makna i dan penyebutannya dimaksudkan untuk menunjukkan "masa" atau "tempat" dari sebuah pekerjaan (Hisyam, tt: 320). Contoh: جلست ناحية ناحية Katabaca nashab (accusative) karena dia adalah dlaraf makân (menunjukkan tempat), sedangkan kata ساعةً juga dibaca nashab (accusative) karena sebagai dlaraf zamân (menunjukkan masa/waktu). Kedua dlarf tersebut pada dasarnya menyimpan makna جلست في jadi kalau ditulis secara lengkap kalimat itu akan berbunyi ,ف

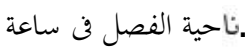

Dalam struktur kalimat ini, âmil yang menashabkan dlaraf tersebut bisa bermacam-macam, yaitu 1) mashdar, misalnya المشي صباحا

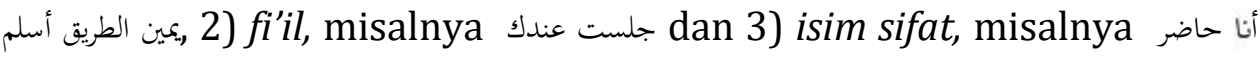
عندك غدا. Selanjutnya âmil-âmil tersebut dari segi keberadaannya dalam kalimat terbagi menjadi dua, yaitu âmil yang boleh dibuang dan âmil yang harus dibuang. Suatu âmil boleh dibuang dengan syarat apabila terdapat petunjuk yang bisa menjelaskan akan keberadaannya. Misalnya; ada seseorang bertanya sebagai berikut: متى جئت؟ kemudian dijawab dengan dlaraf يوَّ الجمعة. Sedangkan suatu âmil harus dibuang apabila 1) maknanya telah melebur kepada isim yang sebelumnya. 'âmil itu adalah kata استقر/مستقر dan kata yang serupa lainnya, serta مررت برجل م didalam kalimat ia berkedudukan sebagai, a) kata sifat, contoh مررت برجل مستقرّ مatimat ini jika ditulis secara lengkap akan berbunyi 
عندك, جاء الذى عندك D) shilah, misalnya. Di dalam kalimat tersebut sebenarnya menyimpan kata استقر, sehingga kalau ditulis lengkap akan berbunyi جاء الذى استقر عندك, c) hâl, misalnya مررت بزيد عندك. Kalimat ini sebenarnya menyimpan kata استقر, sehingga kalau ditulis lengkap akan berbunyi مررت بزيد استقر عندك dan d) khabar, misalnya: زيد عندك. Kalimat inipun sebenarnya juga menyimpan kata مستقر, yang kalau ditulis secara lengkap akan berbunyi زيد مستقرّ عندك ل 2) dlarf itu berada pada sebuah kalimat yang isytighâl. Contoh يوم الخميس صمت فيه.

Berdasarkan contoh-contoh di atas dapat diketahui bahwa nashabnya dlarf disebabkan oleh adanya 'âmil . Sementara dalam situasi tertentu keberadaan 'âmil tersebut harus dibuang. Adanya ma'mûl tapi tanpa adanya 'âmil inilah yang menyebabkan kaidah ini dikategorikan sebagai kaidah yang anomali. Pada dasarnya 'âmil-'âmil tersebut bukanlah dibuang dalam pengertian tidak dibutuhkan, namun sebenarnya 'âmil-'âmil tersebut tetap ada, hanya tidak dinampakkan. Peristiwa ini dalam ilmu bahasa Arab disebut dengan taqdîr. Walaupun demikian dalam perspektif proses belajar mengajar, kasus yang demikian ini tentu bukan sesuatu yang mudah bagi siswa, apalagi bagi pemula. Kasus semacam ini justeru akan menambah keabstrakan kaidah bahasa Arab, karena itulah banyak para linguis yang tidak menyangkal akan kerumitan kaidah itu dan mereka berkata bahwa kaidah bahasa Arab itu sangat dekat dengan cara berfikir filosofis. Mereka menganjurkan agar kaidah-kaidah yang mengedepankan 'i'rab taqdîr, 'i'rab maĥhal dan 'i'rab-'i'rab yang tidak terlalu dibutuhkan sebaiknya ditinggalkan. Di antara mereka adalah Ibn Madlâ (w. 592 H), Syauqi Dhayf (1910-2003 M) dan Tammâm Ĥassân (1918-sekarang) dan lain-lain.

Dengan demikian jelaslah bahwa tindakan membuang 'âmil yang merupakan bagian yang tidak terpisahkan dari ma'mûl-nya ini 
adalah tindakan yang bisa dipersepsikan sebagai usaha mengurangi unsur kelengkapan kalimat, dan ini berarti tidak sesuai dengan kaidah dasar, bahwa setiap ada ma'mûl pasti ada pula 'âmil-nya. Walaupun cara ini merupakan bagian dari cara orang Arab didalam mengekspresikan bahasanya dan telah menjadi bagian kaidah itu sendiri, tapi karena dilakukan dengan melanggar kaidah yang lain, maka kaidah ini tetap dikatakan sebagai kaidah yang anomali (kaidah anomali bukan berarti tidak baik, apalagi salah, pengkategorian anomali hanya karena kaidah itu berbeda atau menyimpang dari kaidah dasar, dan ini sesuatu yang biasa dalam bahasa Arab). Permasalahannya sekarang adalah apakah kehadiran kaidah "keharusan membuang âmil " tersebut memiliki implikasi pada perubahan makna dan maksud dalam kalimat tersebut, atau dengan kata lain setelah terbuangnya âmil tersebut akan terjadi perubahan makna dari kalimat tersebut?.

\section{Mendahulukan khabar atas mubtada'}

Secara umum susunan jumlah ismiyah itu dimulai dari mubtada' dan kemudian baru diikuti oleh khabar. Namun dalam beberapa kasus, banyak dijumpai susunan yang terbalik, yaitu khabar didahulukan atas mubtada', dan ini berarti telah menyimpang dari kaidah dasarnya, yaitu mubtada' berposisi di awal kalimat baru kemudian diikuti khabar. Oleh karena itulah fenomena semacam ini digolongkan sebagai sebuah al-qấidah al-far'iyyah yang anomali. Dinamakan demikian karena fenomena ini selain telah diatur dengan kaidah khusus juga telah tidak sesuai dengan kaidah dasarnya.

Terhadap masalah ini para nûhâh telah berbeda pendapat, ada yang membolehkan mendahulukan khabar atas mubtada', dan ada yang sebaliknya. Para ulama' yang tidak membolehkan adalah para ulama' yang berasal dari Kûfah. Menurut mereka mendahulukan khabar atas mubtada' adalah tidak boleh, karena akan merusak tatanan yang berhubungan dengan dlamîr (kata ganti). Paling tidak mereka menyampaikan dua alasan, yaitu: pertama; jika posisi khabar 
didahulukan atas mubtada', seperti contoh kalimat قائم زيد, maka kata زيد yang semula berkedudukan sebagai "mubtada' yang diakhirkan" akan berubah menjadi فاعل sebab adanya unsur pekerjaan (fi'il) yang terdapat dalam kata قائم yang berposisi sebagai khabar akibat kata tersebut didahulukan atas kata زيد. Kedua; jika posisi khabar didahulukan atas mubtada', maka itu berarti mendahulukan dlamîr (kata ganti) yang terdapat pada kata قائم atas isim zhahir-nya, yaitu زيد padahal yang demikian itu tidak mungkin.

Sedangkan ulama' yang membolehkan mendahulukan khabar atas mubtada'-nya adalah para ulama' yang berasal dari Bashrah. Mereka berargumentasi bahwa isim fấil itu -sebagaimana pada contoh sebelumnya- adalah merupakan فرع (cabang), sehingga kedudukannya terlalu berat untuk beramal yang kemudian bisa merubah posisi زيد sebagai fâ'il . Sedangkan yang berkenaan dengan dlamîr (kata ganti) mereka berargumentasi bahwa pada dasarnya ketika khabar yang mengandung dlamîr itu didahulukan secara lafzhy, secara takdir hakikatnya adalah diakhirkan. Jadi tidak ada alasan untuk tidak boleh mendahulukan khabar atas mubtada'nya.(Kamaluddin, tt: 70-71).

Sementara itu Musthafâ al-Ghalâyainî menegaskan akan diharuskannya mendahulukan khabar atas mubtada'-nya dan kemudian mencatat beberapa situasi dimana diharuskannya mendahulukan khabar atas mubtada'-nya. Situasi-situasi tersebut adalah 1) Apabila mubtada' tersebut berupa nakirah ghairu mufídah, dan khabarnya berupa dlaraf atau jar majrûr. Hal ini karena jika khabar tidak didahulukan atas mubtada'-nya, khabar itu dikhawatirkan dianggap sebagai kata sifat. 2) Apabila khabar berupa isim istifhâm atau yang dimudlafkan kepada isim istifhâm. Hal ini dilakukan karena pada dasarnya isim istifhâm itu adalah awal dan sekaligus inti kalimat. 3) Apabila pada mubtada' mengandung dlamîr 
yang kembali kepada khabar, contoh في الدار صاحبها 4). Apabila khabar itu berupa kata yang pasti dimiliki dan diperuntukkan bagi mubtada'-nya, contoh إنما محمود من يجتهد ,ما خالق إلا الله Kadalah sebuah kata yang pasti dimiliki dan diperuntukkan bagi Allah, demikian juga kata ممود adalah kata yang diperuntukkan bagi orang-orang yang giat (Mushthofa, 2005: 379-380).

Walaupun tidak semua ulama' naĥw sepakat akan keberadaan kaidah dibolehkannya atau bahkan diwajibkannya mendahulukan khabar atas mubtada', namun sebagian besar ulama mengakui akan adanya kenyataan fenomena tersebut. Dan sebagaimana yang telah disampaikan di atas bahwa kaidah itu bersebrangan dengan kaidah dasarnya, yaitu mubtada' harus didahulukan atas khabar. Oleh karena itulah kaidah ini dikategorikan sebagai kaidah yang anomali.

\section{Kesimpulan}

Berdasarkan uraian-uraian di atas, maka dapat disimpulkan bahwa beberapa kaidah bahasa Arab, asal-usul penciptaannya bukan didasarkan atas kepentingan menghadirkan makna baru dalam kalimat. Di antara pola yang digunakan adalah pola al-hadzf (membuang salah satu elemen dalam kata atau kalimat), al-rutbah (merubah posisi kata dari posisi didepan menjadi dibelakang, dan atau sebaliknya). Selain kedua pola itu juga kadangkadang dengan cara melakukan penambahan-penambahan huruf atau kata dalam kalimat, serta pada beberapa kesempatan mengganti atau merubah sesuatu yang memang semestinya dengan sesuatu yang lain. Pola-pola semacam ini selain tidak banyak berpengaruh terhadap makna dalam sebuah kalimat, juga justeru menambah kerumitan tata bahasa bahasa Arab. 


\section{Daftar Rujukan}

Anbary, Abi al- Barakât Abdu al- Raĥmân bin Muhammad bin Abi Sa'id. Kitâb Asrar al-'Arabiyah. Damaskus: al-Majma' al-'Ilmy al-'Araby, tt.

Andalusy, Jamaluddin Muhammad bin Abdullah bin Abdullah al-Thâ'î alJiyânî. Syarkh al-Tashîl li Ibn Mâlik. Pentaĥqiq: Abdurraĥmân Sayyid dan Muĥammad al-Badawî al-Makhtûn, Juz I, tt

Anîs, Ibrahîm. min Asrâr al-Lughah. Kairo : Maktabah Angglo, tt

Arsyad, Azhar. Bahasa Arab dan Metode Pengajarannya. Yogyakarta: Pustaka Pelajar, 2003.

Bertens, K. Ringkasan Sejarah Filsafat. Yogyakarta: Kanisius, 1989.

Bolinger, Dwight L Aspects of Language. New York: Harcourt, Brace \& Word Inc, 1975.

Bravmann, M.M., Studies in Arabic and General Syntax, Cairo, 1953

Chaer, Abdul. Linguistik Umum,. Jakarta: PT Rineka Cipta, 2007. . Gramatika Bahasa Indonesia. Jakarta: PT Rineka Cipta, 1993 . Linguistik Umum. Jakarta: Rineka Cipta, 2003

. Pengantar Semantik Bahasa Indonesia. Jakarta, Penerbit: Rineka Cipta, 2002.

Chomsky, Noam. Aspect of the Theory of Syntax. Cambridge, Mass,: The MIT Press, 1965.

Daĥdah, Antoine. A Dictionary of Arabic Grammar in Charts and Tables. Cet. I, Beirut: Maktabah Libnân, 1981.

Daidâwî, Muhammad. 'Ilmu al-Tarjamah baina al-Nadlariyyât wa al-Tathbîq. Tunis: Dâr al-Ma'ârif lo al-Thibâ'ah wa al-Nasyr, 1992.

Dhayf, Syauqi. Tajdîdu al-Naĥw. Kairo: Dâr al Ma'ârif, 1982. . al-Madâris al-Naĥhwyyah. Kairo: Dâr al-Ma'ârif, 1968. . Kitabu al-Radd 'ala al-Nuhat li Ibni Madha al-Qurthubi. Cet. 3, Mesir: Dâr al- Ma'ârif, tt., 1988.

- Taisîr al-Naĥww al-Ta'lîmî, Qadîman wa Hadîtsan ma'a Nahji Tajdîdihi, Kairo: Dâr al-Ma'ârif, 1983.

. Tajdîd al-naĥhw. Kairo: Dar al Ma'arif, 1982 M. 
Farrâ, Abû Zakariyâ ibn Ziyâd. Ma'âni al-Qur'ân. Pentahqî̀q Aĥmad Yûsuf Najatî dan Muĥammad 'Alî al-Najjâr, Kairo: al-Haiah al-Mishriyyah al-'Âmmah li al-Kitâb, 1980.

Fayyâdl, Sulaiman. al-Naĥw al-'Ashry. Markaz al-Ahrâm, 1995

Ghalàyanî, Syeikh Musthafà. Jâmi’u al-Durûs. juz I, cet. VII, Beirut: Daru al Kutub al Ilmiyah, 2006.

Ĥamlawi, A. Ahmad. Syadz al-'Arfi fi Fanni al-Sharf. Mesir: Al-Bab al-Habibi, 1957.

Ĥassàn, Tammàm. Maqâlât fi al-Lughah wa al-Adab. Jilid II, Cet. 1, Kairo: 'Alamu al-Kutub, 2006.

Maqâlât fi al-Lughah wa al-Adab. Jilid I, Edisi Revisi, Kairo: 'Âlam alKutub, 2006.

Manâhij al-Baĥts fi al-Lughah. Cet. II, Casablanca: Dâr al-Tsaqâfah, 1979.

al-Lughah al-Arabiyah Ma'nâha wa Mabnâha. Mesir: 'Âlam al-Kutub, 1997.

al-Ushul Dirâsah Epistimologiyyah li al-Fikri al-Lughawy "inda al'Arab, al-Naĥw, Fiqhu al-Lughah, al-Balâghah,. Mesir: 'alamu al Kutub, 2000.

Hisyâm, Ibn. Syarh Qathr al-Nadâ wa Ballu al-Shadâ. Penyusun: Muĥy al-Dîn abdu al-Hamîd, Riyadl: Maktabah Riyadl al-Hadîtsah, tt.

Hitti, Philip K. History of the Arabs. Penerjemah: R. Cecep Lukman Yasin dan Dedi Slamet Riyadi, Jakarta: PT Serambi Ilmu Semesta, 2006.

Jinnî, Ibnu. al-Khashâ'is. Pentaĥqiq: Abd al-ㅂamid Handâwî, Jilid I, Kairo: Dâr al-Kutub al-'Ilmiyyah, 2001.

Ni'mah, Fu'ad. Mulakhkhas, Qawâ'id al-Lughah al-'Arabiyah. Juz II, Cet. IX, Damaskus: Dâr.

Sîbawaih. al-Kitâb. pentaĥîiq: Abdu al-salâm Hârûn, Beirut: al-maktabah al'ashriyah, tt.

Sulaimân, Abdu al-Raĥmân 'Ali. Taudlîh al-Maqâshid wa al-Masâlik bi Syarkhi Alfiyati Ibn Mâlik li al-Murâdi. Juz I, Mesir: Dâr al-Fikr al-Araby, 2001.

Syihab, M. Quraish. Orientalisme. dalam Jurnal Studi al Qur'an, Vol, No. 2, 2006. 
Thu'aimah, Rusydi Aĥmad dan Muammad al-Sayyid Mannâ. Tadrîs alArabiyyah fî Ta'lîm al-'Ām: Nadlariyyât wa al-Tajârib. Kairo: Dâr al-Fikr al-'Ārabi, Cet. ke-1, 2000. 